\title{
Sexualidade e disciplina do trabalho na ordem social burguesa
}

\author{
Pablo Biondi ${ }^{1}$
}

Resumo: O objetivo do presente artigo é identificar uma conexão entre as formas capitalistas de controle e influência sobre a sexualidade e a disciplina do trabalho que é própria da sociedade burguesa e de sua ideologia. Deve-se considerar, como ideologia, uma compulsão interna que coloca o sujeito em movimento e que o constitui como um ente autômato dessa sociedade, capaz de entregar voluntariamente sua força de trabalho no mercado, livre de coerções externas e extraeconômicas. A categoria do trabalho, sob o modo capitalista de produção, está inevitavelmente associada à forma valor, assim como o valor está associado aos padrões de gênero da modernidade. Esse arranjo social conspira contra a livre fruição das novas identidades sexuais, já que a ordem social burguesa impõe normas heterossexistas, encontrando suporte relativo na família nuclear tradicional para fins de garantir a reprodução ampliada da força de trabalho. Portanto, o artigo pretende demonstrar que as restrições sociais à diversidade sexual estão enraizadas na sociedade burguesa, particularmente nas suas categorias constitutivas.

Palavras-chave: sexualidade; disciplina do trabalho; capitalismo.

Abstract: The current article's goal is to identify a connection between capitalist forms of control and influence over sexuality and the labor discipline which is proper of bourgeois society and its ideology. It must be considered, as ideology, an inner compulsion that moves the subject and constitutes him as an automate being from this society, able to voluntarily deliver its labor power in market, free from

\footnotetext{
${ }^{1}$ Professor de "Ética e teorias da justiça" da Faculdade de Direito de São Bernardo do Campo. E-mail: pablobiondi@gmail.com.
} 
external and extra-economical coercions. The category of labor, under capitalist mode of production, is inevitably associated to value form, just like value is associated to modernity's gender patterns. This social arrangement conspire against the unconstrained fruition of the new sexual identities, since bourgeois social order imposes heterosexist rules, finding relative support in traditional nuclear family in order to ensure the expanded reproduction of labor power. Therefore, the article intends to demonstrate that social restrictions to sexual diversity are rooted in the bourgeois society, particularly in its constitutive categories.

Keywords: sexuality; labor discipline; capitalism.

\section{Introdução}

O tema da sexualidade ainda carece de muitas elaborações no âmbito do marxismo, mas a literatura já existente pode oferecer perspectivas extremamente instigantes, inclusive em contraponto às análises pós-modernas dominantes. Parece-nos que o grande desafio de uma investigação marxista acerca desse assunto é o de captar as relações históricas entre as formas sociais do capital, sobretudo aquelas que derivam diretamente da forma valor, e os elementos da vida social que tocam de modo mais imediato os comportamentos e as identidades sexuais, como é o caso da família nuclear tradicional.

Para examinar o ponto de encontro entre as determinações materiais características da sociedade capitalista e as contradições da fenomenologia sexual nessa sociedade, entendemos que o aspecto ideológico e disciplinar da forma trabalho assalariado, uma derivação direta do valor e também do capital (mantendo com ele uma contradição determinada que fundamenta todo o sistema social burguês), tem algo de importante a revelar.

Na tentativa de uma análise com esse viés, empreenderemos um estudo do liame entre o capitalismo e as categorias de gênero e sexualidade. Em seguida, faremos um exame sobre a noção de ideologia e sua atuação concreta enquanto disciplina do trabalho

132 Sexualidade e disciplina do trabalho... 
na ordem social burguesa, o que deve nos capacitar para compreender melhor a especificidade da repressão capitalista contra as expressões da sexualidade que destoam da referência heteronormativa. Esperamos demonstrar, assim, que a LGBTfobia é intrínseca ao capitalismo.

\section{Capitalismo e gênero}

O modo capitalista de produção, mais do que qualquer outro, empenha-se em construir uma sociedade à sua imagem e semelhança, submetendo toda a ordem social aos seus condicionamentos essenciais: a divisão mercantil do trabalho, a acumulação de capital, o mecanismo econômico e contratual de coleta do excedente, os métodos de captura desse excedente etc. Trata-se de modelar as formações sociais de sorte que todos os seus aspectos estejam subordinados à reprodução do capital enquanto eixo de toda a vida material. Em função dessa modelagem capitalista da totalidade social, os fenômenos de gênero e sexualidade exigem uma análise que indique os traços específicos que lhes são atribuídos pela sociedade burguesa.

As opressões contra o gênero feminino e contra as relações homossexuais, pelo fato de antecederem historicamente o capitalismo, infundem no observador uma tentação de considerá-las como arcaísmos insistentes ou como nova expressão do antigo patriarcado. Esta, no entanto, é uma maneira incorreta de problematizar o assunto. Por mais que possamos eventualmente empregar conceitos que correspondem ao peso social do passado, devemos manter nossos olhos no presente, compreendendo as formas particulares pelas quais o modo de produção capitalista reproduz em seu proveito essas opressões, integrando-as no conjunto da sociabilidade burguesa.

No que diz respeito ao gênero, priorizamos as análises que destacam a especificidade dessa questão nos marcos do capitalismo. A abordagem de Roswitha Scholz vai nesse sentido de forma contundente, razão pela qual a tomaremos como uma referência fundamental. A autora alemã teve o mérito de investigar com 
profundidade a "anatomia econômica" da sociedade capitalista, partindo desse domínio para apontar o lugar que a ordem capitalista oferece às mulheres de um modo geral, ou seja, o modo singular como ela constitui as suas próprias delineações de gênero, ainda que existam algumas semelhanças com certas experiências pré-capitalistas.

Scholz demonstrou que a forma capitalista da riqueza, é dizer, o valor, não é sexualmente neutra, na medida em que pressupõe uma cisão ou dissociação entre uma esfera produtiva/pública e uma esfera reprodutiva/privada, o que conduz ao confinamento doméstico da mulher e à opressão contra ela. Nessa abordagem, a delimitação do gênero feminino e as qualidades que lhe são imputadas são um suporte necessário à forma do trabalho abstrato na sociedade burguesa. O desprestígio da mulher diante do homem corresponde, assim, ao desprestígio das atividades domésticas, historicamente imputadas ao gênero feminino, em relação ao trabalho produtivo, que gera valor diretamente:

Essa estrutura básica da relação de valor tem correspondência com a formação de uma esfera privada e outra pública. A esfera privada, consequentemente, é ocupada pelo tipo ideal "feminino" (família, sexualidade etc.), ao passo que a esfera pública ("trabalho" abstrato, Estado, política, ciência, arte etc.) é "masculina". De forma ideal, a mulher seria assim o "recosto" social para o homem, que age na esfera pública (SCHOLZ. 1996, p. 18).

A tese de Scholz aprofunda o raciocínio iniciado por autoras c omo Angela Davis (2005), que já haviam identificado, na cisão capitalista entre um domínio doméstico/privado e um domínio profissional/público, um elemento de delimitação da opressão do capital contra as mulheres, haja vista a hierarquia do masculino sobre o feminino que ela implica. Antes do capitalismo, recorda Davis, o trabalho doméstico era muito mais amplo e diversificado, envolvendo o cultivo e a fabricação de alimentos, assim como a manufatura de

134 Sexualidade e disciplina do trabalho... 
roupas e outras utilidades. Ainda que com recorte de gênero, essas atividades não traçavam uma linha tão definida entre o masculino e o feminino na produção. A mulher era uma artesã dotada de diversas habilidades que foram expropriadas pela indústria capitalista em seu movimento de subsunção real do trabalho ao capital.

Com a industrialização capitalista, ou seja, com a subsunção real do trabalho ao capital, as economias de subsistência, nas quais as mulheres conservavam algum tipo de autonomia, ainda que com restrições, foram aniquiladas. A produção doméstica da mulher foi substituída pelo trabalho doméstico tal como o conhecemos hoje. E se antes dessa fase da indústria predominava a utilidade concreta dos produtos na esfera domiciliar, com o sistema fabril houve uma inversão, favorecendo-se o valor de troca dos bens produzidos no espaço específico da produção, agora dissociado fortemente do espaço da reprodução. Estabeleceu-se não apenas uma separação física entre o lar e o local de trabalho (a fábrica), como também uma separação estrutural entre a economia doméstica e a economia voltada para o lucro. E ao não gerar lucro, o trabalho doméstico foi tido como inferior ao trabalho assalariado. Foi assim que se forjou a figura da dona de casa, ainda que muitas mulheres estivessem numa situação muito distinta, como era o caso das proletárias incorporadas na indústria (DAVIS, 2005, p. 226).

Por conseguinte, essa desvalorização da mulher implica uma depreciação de mercado na sua força de trabalho, tornando o contingente feminino uma fonte de mão de obra mais barata e dividindo os trabalhadores pela prática de condutas opressivas no interior da própria classe dos assalariados. Mesmo ao "cruzar o Rubicão" da divisão do trabalho e ingressar na esfera pública/profissional, o gênero feminino é submetido a discriminações evidentes, a começar pelo desnível na remuneração e pelas dificuldades de ascensão profissional. Ao se colocar no interior do espaço produtivo do capital, é como se a mulher adentrasse num ambiente hostil, numa localidade onde ela é considerada uma forasteira ou uma intrusa. A economia capitalista, 
certamente, beneficia-se disso e amplia o excedente que coleta do conjunto dos assalariados, sobretudo em virtude da circunstância de que as proletárias, ao se engajarem na seara profissional, seguem atuando no âmbito doméstico, desonerando o capital de parte expressiva dos custos de reprodução da força de trabalho (CORREIA e BIONDI, 2011).

Percebe-se, então, que a ordem social burguesa institui, inapelavelmente, uma dissociação entre o masculino e o feminino, associando o primeiro às qualidades públicas dominantes e o segundo às inclinações domésticas, ligadas a tarefas reprodutivas, aos cuidados do lar. O conjunto das características atribuídas às mulheres, é dizer, a expectativa construída socialmente em relação a elas, como é notório, orbita em torno da figura da maternidade e da função de esposa, além de remeter a uma imagem afetiva e emocional que se opõe à austeridade e à racionalidade da esfera dos negócios, do ambiente profissional. Eis a base específica da opressão burguesa de gênero:

O ponto de partida necessário não é meramente o valor, mas a relação de valor-dissociação como uma estrutura social fundamental que corresponde ao pensamento universalista androcêntrico. Afinal, o queéimportante aqui nãoé simplesmente que o tempo médio de trabalho ou o trabalho abstrato determina o dinheiro como forma equivalente. Mais importante é a observação de que o próprio valor deve definir como menos valioso e dissociar o trabalho doméstico, o não-conceitual, e tudo relacionado à não-identidade, o sensorial, afetivo e emocional ${ }^{2}$ (SCHOLZ, 2014, p. 132).

Ohomem é, assim, a imagem social do valor, é a identidade oficial do guardião de mercadorias, estando atrelado às atividades produtivas (geradoras de valor), cabendo à mulher na sociedade do capital,

\footnotetext{
${ }^{2}$ Informamos que todas as citações de texto em língua estrangeira serão traduzidas por nós livremente.
}

136 Sexualidade e disciplina do trabalho... 
em contrapartida, o papel de sombra do homem por excelência, de suporte ao gênero engajado no mercado, e que é edificado ideologicamente como o autêntico frequentador da arena mercantil. Apesar da abstração do indivíduo na sociabilidade capitalista, o elemento masculino está implícito na categoria do sujeito (e em suas distintas derivações de cidadania), restando ao feminino, nesse estado de coisas, a posição inferiorizada de "segundo sexo".

\section{Capitalismo e sexualidade}

Ao tecer relações de gênero desiguais e rígidas, e que funcionam como um anteparo social para a forma valor e para a acumulação de capital, o capitalismo também avança sobre o domínio da sexualidade, impondo um determinado modelo conforme os seus padrões e as suas necessidades econômicas. Nesse campo, inclusive, pode-se dizer que ele cumpriu um papel histórico relativamente progressivo, embora ele cotidianamente atue em sentido contrário ao progresso que permitiu.

Expliquemo-nos. Ao erodir as economias de subsistência, a indústria capitalista, no curso de um par de séculos, disseminou o assalariamento e dissolveu a produção doméstica familiar. Em comparação com a vida rural, a vida urbana nos centros industriais, marcada pelo assalariamento, acentuou a separação entre a esfera doméstica e a esfera de trabalho, tornando a primeira um espaço exclusivo de reprodução (WOLF, 2009, p. 31). As famílias perderam o caráter de unidades produtivas autossuficientes, convertendo-se em núcleos de fornecimento de mão de obra livre para o mercado de trabalho - livre na acepção capitalista, isto é, desembaraçada de vínculos orgânicos com a terra e de laços feudais. A família proletária, assim, não seria uma célula econômica autônoma, e sim um ponto de apoio para o indivíduo comercializar a sua força de trabalho numa esfera profissional bem delimitada. Mais do que isso, essa nova unidade familiar depende agora da aquisição de víveres no mercado,

caderno cemarx, nº $10-2017 \quad 137$ 
e seu centro passa a ser a sua renda salarial, já que o capital conseguiu mercantilizar o acesso aos itens mais elementares à vida material.

Ocorre, no entanto, que a venda individual da mercadoria força de trabalho cria condições para uma vida sexual independente, ao contrário do modelo anterior, em que a produção é decididamente familiar, e que por isso dependia de uma quantidade considerável de filhos empenhados na atividade econômica (em regra, no campo). $\mathrm{O}$ assalariamento promovido pelo capitalismo em escala ampliada, ao subverter esse tipo de família, permitiu que a associação conjugal entre as pessoas estivesse, enfim, desvinculada de uma necessidade econômica de subsistência. Cada indivíduo torna-se, enquanto assalariado, capaz de prover a si próprio com autonomia, ainda que siga encarregado do trabalho doméstico (trabalho este que continua sendo exercido, na imensa maioria dos casos, pelas trabalhadoras). De qualquer maneira, o diferencial colocado é a superação do imperativo de procriação, conforme constatou John D’Emilio:

Tendo o trabalho assalariado se espalhado e a produção se tornado socializada, tornou-se então possível liberar a sexualidade do "imperativo" de procriar. Ideologicamente, a expressão heterossexual tornou-se um meio de estabelecer intimidade, promover felicidade e experimentar prazer. Ao privar o domínio doméstico de sua independência e ao encorajar a sexualidade a se separar da procriação, o capitalismo criou condições que permitem que alguns homens e mulheres organizem uma vida pessoal em torno de sua atração erótica/emocional por seu próprio sexo. Ele tornou possível a formação de comunidades urbanas de lésbicas e gays, e, mais recentemente, de uma política baseada na identidade sexual. (D’EMILIO, 1983, p. 104)

Há que se ressaltar que D'Emilio não pretende dizer que o desejo homossexual ou as relações homoeróticas tenham se originado no capitalismo. A evidência histórica só pode indicar o contrário. O que a época histórica capitalista permitiu, diferentemente, foi a

138 Sexualidade e disciplina do trabalho... 
formação de autênticas identidades homossexuais e bissexuais, é dizer, a concretização de uma vida pessoal baseada numa afetividade LGBT. Antes disso, as uniões eram necessariamente heterossexuais, cabendo aos desejos homoafetivos uma existência marginal, mesmo nos casos em que eles fossem admitidos ${ }^{3}$.

É de se notar, não obstante, que a origem moderna do fenômeno das identidades LGBT fez-se acompanhar da contradição capitalista que já apresentamos: o mesmo processo que estabeleceu a divisão de gêneros no sentido da dissociação do valor, ao se desenvolver, abriu caminho para uma vida sexual não necessariamente condicionada pela procriação. Para os núcleos familiares proletários, gerar filhos não é uma providência imposta pela atividade econômica a que os pais se dedicam, mas antes o contrário, ou seja, algo que se contrapõe à carreira profissional - e se espera que o gênero feminino se "sacrifique" nas tarefas reprodutivas, justamente para que o homem, como "titular" do acesso ao mercado de trabalho, tenha a prioridade na produção e na distribuição do valor.

Ainda assim, a possibilidade de uma diversificação nas identidades sexuais, de novas formas de exercício da sexualidade com base no afeto e na livre disposição individual, deve ser reconhecida como um "mérito" histórico do capitalismo, como um enriquecimento da experiência cultural humana - por mais que isto seja um efeito colateral, não correspondendo a nenhum tipo de objetivo estratégico da burguesia. Porém, o próprio capitalismo atua contra a diversidade

\footnotetext{
${ }^{3}$ No conhecido caso da polis grega na Antiguidade clássica, há que se entender que as relações de caráter homossexual expressavam apenas a liberdade sexual dos chefes masculinos de cada unidade familiar. Os núcleos familiares da Grécia Antiga eram inteiramente ancorados na relação heterossexual (e de dominação direta) entre o patriarca e a esposa, sendo que o desejo homoafetivo jamais poderia, naquelas condições, sedimentar uma estrutura como a família, tampouco uma identidade lastreada nesse tipo de orientação sexual. Trata-se de uma decorrência lógica do patriarcado da Antiguidade enquanto estrutura familiar de uma sociedade que não conhecia a separação entre produção e reprodução.
} 
que ele fomentou inicialmente, revelando-se um obstáculo à fruição completa da experiência homoafetiva.

D'Emilio adverte que se de um lado o capitalismo enfraquece a família tradicional ao individualizar a renda econômica, ensejando que gays e lésbicas consigam viver fora do modelo familiar estabelecido, de outro ele pressiona ideologicamente os indivíduos a comporem famílias e a terem filhos, enaltecendo, assim, a heterossexualidade em desfavor da homossexualidade. Desse modo, “a elevação da família à proeminência ideológica garante que a sociedade capitalista reproduzirá não apenas filhos, mas também heterossexismo e homofobia" (D’EMILIO, 1983, p. 110).

Pela afirmação da família heterossexual monogâmica, o capital reitera os padrões de gênero e incentiva a perpetuação da mão de obra. E cumpre observar que só lhe é dado fazê-lo ideologicamente, uma vez que a família segue sendo um fenômeno do domínio privado-doméstico. Quer dizer: como o capitalismo não socializou a organização familiar, apesar de tê-lo feito com a produção, exigese que cada indivíduo e cada núcleo doméstico decida livremente, sem a intervenção de uma direção política, que deve ter filhos e que o sentido da vida consiste no triunfo profissional e na procriação, gerando-se trabalhadores autômatos, dispostos a se dedicaram ao regime do assalariamento a partir de um convencimento íntimo, de uma "internalização" ideológica de certas normas disciplinares.

\section{Sociedade burguesa, ideologia e disciplina do trabalho}

Agora que vimos como o capitalismo atua contraditoriamente sobre a sexualidade, cumpre acrescentar outro fator determinante: a ideologia. O que vemos na sociedade burguesa é uma espécie de "dirigismo" ideológico sobre as condutas sexuais e, acima de tudo, sobre as identidades dos indivíduos no tocante à sua orientação sexual. Mas um dirigismo ideológico em sentido rigoroso: contra as manifestações diversificadas da sexualidade, a ordem social

140 Sexualidade e disciplina do trabalho... 
capitalista tendeu a substituir a repressão direta estatal pela difusão de concepções heteronormativas, especialmente pelo reforço da figura da família heterossexual monogâmica. E esta formulação ideológica, a seu turno, está vinculada a uma lógica disciplinar inerente ao trabalho assalariado que se difunde no âmago do proletariado e que potencializa a dominação do capital.

Antes de examinarmos o elo entre a opressão sexual promovida pelo capitalismo e a sua disciplina do trabalho, convém estudar mais atentamente o tema da ideologia e sua relação com a forma trabalho. Por ideologia, devemos entender o processo de interpelação dos sujeitos da sociedade burguesa, no qual eles próprios aderem aos padrões comportamentais, sem a necessidade de elementos coercitivos que atuem imediatamente - sendo que esta adesão está amparada nas aparências sociais, nas formas existentes na superfície do sistema capitalista, e que promovem um contraste entre aparência e essência, num mecanismo de alusão-ilusão (ALTHUSSER, 2007, p. 78).

Sob o jugo do capital, a massa dos indivíduos é compelida economicamente a vender sua força de trabalho em troca de salário. Conforme argumentamos em outra ocasião, a compulsão econômica em si mesma não explica por completo a normalidade do assalariamento. Ao contrário do que se passa sob a escravatura e a servidão, identificase no regime salarial "um elemento operante de 'convencimento' que, como em nenhuma outra sociedade, disciplina a força de trabalho e a coloca em movimento sem que ela seja coagida militarmente a trabalhar" (BIONDI, 2017, p. 94). Esse elemento é a ideologia, a qual, segundo nosso entendimento, consiste numa forma de consciência, ou mesmo de inconsciência (ALTHUSSER, 1979, p. 206), específica do capitalismo, pois esse é o único modo de produção baseado na extorsão do excedente à base de meios puramente econômicos.

É próprio do capitalismo açambarcar o sobreproduto por intermédio de um contrato de trabalho, no qual o proletário concede livremente (livre no sentido jurídico formal) ao patrão o direito de 
consumir sua força de trabalho. E são os próprios proletários que se engajam na busca da venda dessa mercadoria. Lançando-se nessa empreitada, os assalariados são movidos não meramente pela fome, pela carência, mas antes por uma ideologia jurídica que o qualifica como um indivíduo livre e responsável por seu destino - e que o estimula ideologicamente como trabalhador produtivo. Comparando o escravo e o assalariado, Marx (1978, p. 62-63) constata que o primeiro "só trabalha sob pressão de um temor exterior, e não, para sua existência - que, ainda que não lhe pertença, não obstante, está garantida", enquanto que o segundo "trabalha impulsionado por suas necessidades (wants)", sendo que "a consciência (ou melhor, a representação) de uma determinação pessoal livre, da liberdade, assim como o sentimento (...) de responsabilidade (responsability) ligado àquela, fazem deste um trabalhador muito melhor do que aquele".

Resulta daí que a ideologia, em sua conformação capitalista de liberdade jurídica - já que, no capitalismo, todos os indivíduos são formalmente livres, iguais e proprietários enquanto possuidores abstratos de mercadoria -, faz com que os indivíduos das classes dominadas "pareçam 'funcionar' por si mesmos, reproduzindo as condições de seu próprio subjugamento ao capital, sem que seja necessário o uso da violência direta", ou seja, "sem a intervenção imediata e permanente dos aparelhos repressivos do Estado" (NAVES, 2014, p. 90).

Transformando os trabalhadores em entes autômatos, conduzidos por comandos ideológicos internos, o capitalismo infunde neles, além de um senso de responsabilidade, uma disciplina particular. Essa característica despontou em plenitude com a ascensão da indústria capitalista propriamente dita, isto é, com a subsunção real do trabalho ao capital. O controle disciplinar do trabalho, compreendendo as regras de diminuição dos tempos mortos (improdutivos) no processo de produção e a obsessão pela coleta eficiente do sobreproduto, é típico da fase inaugurada com a revolução industrial do século XVIII.

\begin{tabular}{c|l}
142 & Sexualidade e disciplina do trabalho...
\end{tabular} 
Com a indústria capitalista, ou melhor, com o modo de produção especificamente capitalista, instaura-se o imperativo de controle disciplinar do tempo do trabalho e do uso do tempo no geral. Edward Thompson (1984, p. 288) observa que "as sociedades industriais maduras de todo tipo se distinguem porque administram o tempo e por uma clara divisão entre 'trabalho' e 'vida'". O valor que o indivíduo trabalhador gera para o capital é criado na esfera do trabalho, de modo que a vida dele (a esfera doméstica, o consumo, as fruições) é um apêndice do momento laboral. Tudo gira em torno do trabalho assalariado, do trabalho produtivo para o capital: atividades alheias à fabricação ou à distribuição do valor devem ser reduzidas ao mínimo. $\mathrm{O}$ que se espera do assalariado é que ele não apenas seja um obreiro diligente, mas que esteja, ainda, à disposição do capital constantemente, ainda que como integrante de um exército industrial de reserva.

Vê-se então que, na ordem social burguesa, o trabalho é também uma determinação disciplinar. O capital controla o tempo de trabalho e, indiretamente, o tempo de não-trabalho, isto é, o tempo de "vida". Em adendo, o trabalho é, em sua oposição ao capital, uma forma histórica capitalista, um componente da lei do valor que designa a mercantilização da força de trabalho e a sua capacidade, sob as condições sociais burguesas, de originar o valor. Anselm Jappe (2006, p. 94) percebeu que "trabalho assalariado e capital mais não são do que dois estados de agregação da mesma substância: o trabalho abstrato coisificado em valor", o que é o mesmo que dizer que "são dois momentos sucessivos do processo de valorização, duas formas do valor". O trabalho assalariado é, pois, um dos pilares da sociedade burguesa, e não deve causar espanto que ele assuma um estatuto ideológico e mesmo fetichista no âmbito dessa sociabilidade.

A dimensão ideológica do trabalho é nítida na mistificação contida no assalariamento, o qual, sob a égide da igualdade jurídica do contrato de trabalho, escamoteia a apropriação da mais-valia. 
A ideologia do trabalho está na inversão que se verifica: o trabalhador acredita que o trabalho é a fonte da fortuna pessoal, que qualquer indivíduo zeloso e esforçado pode conquistar a sua fortuna e que a diferença entre ele e o capitalista seria a qualidade do labor desempenhado ou a diligência na administração da riqueza. Todavia, o labor prestado pelo obreiro apenas enriquece o capital, que se define pela capacidade de sugar a riqueza e por sua natureza improdutiva por excelência. $\mathrm{O}$ funcionamento da ideologia consiste na arte pela qual o capital mobiliza os assalariados na produção e na distribuição do valor, e de modo a fazê-los trabalhar acreditando que agem no seu próprio interesse, e não no interesse de uma potência parasitária.

Porém, na qualidade de um "sistema de representações que asseguram a relação dos indivíduos com as tarefas fixadas pela estrutura da totalidade social" (SAMPEDRO, 2010, p. 44-45), a ideologia não se encerra na "fetichização" do seu objeto delimitado. Ela deve "dialogar" com os pontos sensíveis da reprodução das relações sociais, engendrando uma totalidade disciplinar constitutiva do proletariado, um controle ideológico que ultrapassa o local de trabalho e domina a existência dos indivíduos, atuando, inclusive, nos redutos de sua intimidade sexual.

\section{Ordem capitalista, ideologia do trabalho e repressão sexual}

Como vimos anteriormente, a sociedade capitalista confia a reposição da força de trabalho a núcleos familiares de assalariados, quer dizer, a famílias obreiras que encontram seu sustento no bojo do mercado, e não numa esfera de produção de subsistência (economia de forma natural). Em acréscimo, o modo de produção capitalista, ao introduzir um ideal de empreendedorismo, conquista pessoal e individualidade, incentivou igualmente a acumulação patrimonial privada e a sua continuidade hereditária, o que demandou uma estrita moralidade sexual, sobretudo no que diz respeito às mulheres.

144 Sexualidade e disciplina do trabalho... 
Quanto a isso, a estrutura familiar cumpriu e segue cumprindo um papel essencial.

A família nuclear serve à classe dominante, ainda hoje, como um meio barato de manutenção, perpetuação e disciplina da força de trabalho, incubando normas sexuais rígidas e papeis de gênero definidos (WOLF, 2009, p. 34), fazendo-o muitas vezes a partir de práticas padronizadas inconscientes. Essas práticas são, em grande medida, uma continuação dos regramentos oitocentistas acerca da da sexualidade, aglutinados naquilo que se convencionou chamar de moralidade vitoriana. Essa moralidade consiste num reforço aos papéis de gênero, os quais estão umbilicalmente ligados à forma valor, conforme já discutido.

Assim sendo, cumpre perceber que os núcleos familiares não são antros abstratos de conservadorismo moral, mas antes engrenagens no interior do maquinário social capitalista, desempenhando funções de reprodução da sociabilidade burguesa. No domínio familiar, os indivíduos são ideologicamente constituídos de acordo com os valores vitorianos, ainda que com certas adaptações. Isso porque o ingresso do contingente feminino do proletariado no mercado e a conformação da comunidade LGBT, por força de fenômenos econômicos do próprio capitalismo, impede que a moral vitoriana consiga se afirmar plenamente, embora ela seja sempre uma sombra pairando sobre a sociedade, atuando com mais vigor nas conjunturas que exigem um reforço das funções domésticas e reprodutivas (WOLF, 2009, p. 62). Não à toa, o discurso de enaltecimento da família tradicional, apesar de todas as transformações sociais do século $\mathrm{XX}$, desfruta de lugar cativo no debate público. Além disso, nas primeiras oportunidades, o capital realça os paradigmas de gênero, como que reconstituindo o que seria, para ele, a ordem natural das coisas.

No entanto, mais do que indicar o que seria uma disposição natural de posições sociais, a sociedade burguesa utiliza esses paradigmas com objetivos disciplinares e, numa acepção rigorosa, ideológicos. A normatização sobre a sexualidade e os gêneros 
associa-se diretamente às funções sociais do trabalho assalariado. Assim ocorre em função do fato de que a moral vitoriana internaliza nos indivíduos e nas unidades familiares o controle sexual, canalizando as energias e atenções para o labor. A austeridade moral capitalista não se compatibiliza com uma vida sexual que, uma vez desconectada de finalidades procriativas, não se insere no esforço de reprodução ampliada da força de trabalho. Na visão do capital, uniões inférteis são uniões improdutivas, incapazes de abastecer as necessidades de mão de obra do mercado, ou ainda, de se consagrar fielmente à lógica do trabalho, dado que os que vivem sob a ditadura dessa entidade (a contraface do capital) devem ocupar-se também da sua reposição constante. Podemos concordar com Relmut Reiche (1970, p. 38) na constatação de que a ordem social capitalista estabelece um tipo de compulsão interna que reduz todas as atividades e qualidades humanas à sua utilidade relativa ao processo de produção, cultivando nas pessoas a concepção de que nada é digno ou respeitável se não estiver relacionado com o trabalho, com o esforço e o sacrifício de trabalhar. Tudo se torna recompensa pelo trabalho, ou então, ao contrário, um desperdício da oportunidade de trabalhar.

Cabe reconhecer que o capitalismo não foi o único modo de produção a estabelecer diretrizes comportamentais sexuais para os indivíduos, tampouco foi exclusivo na celebração do intercurso heterossexual monogâmico como expressão considerada legítima da sexualidade. Não obstante, a sociedade burguesa destaca-se das demais ao realizar um tipo de repressão sexual que se destina a uma organização da vida em torno do trabalho, ou seja, a uma canalização das possibilidades sexuais para o domínio restritivo daquilo que é admitido pela lei do valor e por suas feições de sexualidade e gênero. E mais do que isso, a ordem social capitalista foi a primeira a gerar essas repressões em escala mundial, levando às colônias diversas instituições punitivas contra LGBTs - no caso, instituições e concepções desenvolvidas nas metrópoles imperialistas.

146 Sexualidade e disciplina do trabalho... 
Finalmente, há que se adicionar que, mesmo nas conhecidas formas pré-capitalistas de opressão sexual (como a escravidão, que transformava o escravo em objeto de satisfação erótica de seus donos, e as perseguições promovidas pela Igreja católica medieval contra os comportamentos sexuais "desviantes"), o que se observava era o cerceamento ou a imposição de desejos e condutas sexuais. Com o capitalismo, nota-se uma opressão muito mais incisiva: mais do que os comportamentos, agride-se a própria identidade sexual do indivíduo, antes inexistente nos parâmetros hoje conhecidos.

\section{Conclusão}

Verifica-se à luz do exposto que o capitalismo, apesar de ter abalado certos elementos da família nuclear tradicional, nutriu-se fortemente desse modelo, chegando mesmo a aprofundar os papéis de gênero que lhe são correlatos nos marcos da lei do valor, dissociando uma esfera mercantil masculina de uma esfera doméstica feminina. Essa rigorosa demarcação de gênero sustenta a referência heterossexual e monogâmica da família, atribuindo-lhe a função de repor a mão de obra - contrariamente, pois, às possibilidades de união desconectadas do interesse de procriação que o capitalismo propiciou.

Ao pressionar os indivíduos para uniões aptas à procriação, o capital exerce sobre eles uma disciplina atrelada à lógica do trabalho, e que coloca o dever de trabalhar e de abastecer o mercado de trabalho com mais trabalhadores. O livre exercício da sexualidade, então, acaba sendo restringido pelos imperativos econômicos capitalistas relativos à disponibilidade da mercadoria força de trabalho. Apenas assim é possível entender porque a sociedade burguesa, ostentando jubilosamente a ilusória bandeira da igualdade jurídica, priva dessa igualdade os indivíduos LGBT, particularmente aqueles situados no proletariado, dado que não lhes é possível desfrutar de um consumo compensatório e segregacionista ("Pink Money").

caderno cemarx, nº $10-2017 \quad 147$ 
Não sendo sequer capaz de ofertar uma cidadania completa (igualdade formal) aos LGBTs, o capitalismo dá testemunho de sua exaustão enquanto modelo civilizatório, apontando para a urgência de sua superação revolucionária. A luta contra a exploração capitalista, dessa maneira, deve contemplar, outrossim, a luta contra as amarras que constrangem a sexualidade humana e sufocam a diversidade.

\section{Referências bibliográficas}

ALTHUSSER, L. A favor de Marx, 2. ed. Tradução de Dirceu Lindoso. Rio de Janeiro: Zahar, 1979.

Aparelhos ideológicos de Estado: nota sobre os aparelhos ideológicos de Estado. Tradução de Walter José Evangelista e Maria Laura Viveiros de Castro. São Paulo: Graal, 2007.

BIONDI, P. Não fale em crise, trabalhe: sobre a ideologia do trabalho. Revista Direitos, Trabalho e Política Social, n. 4, v. 3, jan-jun 2017, p. 90-110.

CORREIA, M. O. G. e BIONDI, P. Uma leitura marxista do trabalho doméstico. Revista LTr, n. 3, v. 75, mar. 2011, p. 311-318.

DAVIS, A. Mujeres, raza y clase. Traducción de Ana Varela Mateos. Madrid: Alcal, 2005.

D'EMILIO, J. Capitalism and gay identity. In: SNITOW, A.; STANSEL, C.; THOMPSON, S. (eds.). Powers of desire: the politics of sexuality. New York: Monthly Review, 1983.

JAPPE, A. As aventuras da mercadoria: para uma nova crítica do valor. Tradução de José Miranda Justo. Lisboa: Antígona, 2006.

148 Sexualidade e disciplina do trabalho... 
MARX, K. O capital: livro I, capítulo VI (inédito). Tradução de Eduardo Sucupira Filho. São Paulo: Livraria Editora Ciências Humanas, 1978.

NAVES, M. A questão do direito em Marx. São Paulo: Outras Expressões; Dobra, 2014.

REICHE, R. Sexuality and class struggle. Translated by Susan Bennett. London: NLB, 1970.

SAMPEDRO, F. A teoria da ideologia de Althusser. Tradução de Márcio Bilharinho Naves. In: NAVES, M. B. (org.). Presença de Althusser. Campinas: Unicamp, Instituto de Filosofia e Ciências Humanas, 2010.

SCHOLZ, R. O valor é o homem: teses sobre a socialização pelo valor e a relação entre os sexos. Tradução de José Marcos Macedo. Revista Novos Estudos, São Paulo, n. 45, 1996, p. 15-36.

Patriarchy and commodity society: gender without the body. In: LARSEN, N.; NILGES, M.; ROBINSON, J.; BROWN, N. (eds.). Marxism and the critique of value. Chicago: MCM, 2014.

THOMPSON, E. P. Tradición, revuelta y consciencia de clase: estudios sobre la crisis de la sociedad preindustrial. Traducción de Eva Rodriguez. Barcelona: Editorial Crítica, 1984.

WOLF, S. Sexuality and socialism: history, politics and theory of LGBT liberation. Chicago: Haymarket Books, 2009. 